\title{
A preliminary study of geological variation of in-situ gamma dose rate in the vicinity of coal-fired power plants
}

\author{
Vu Ngoc Ba ${ }^{1,2}$, Bui Ngoc Thien ${ }^{2,3}$, Truong Thi Xuan Truong ${ }^{2,3}$, Nguyen Quang Dao ${ }^{2,3}$, Le Xuan Thuyen ${ }^{2,4}$, \\ Le Cong Hao ${ }^{1,2,3}$, Truong Thi Hong Loan ${ }^{1,2,3}$
}

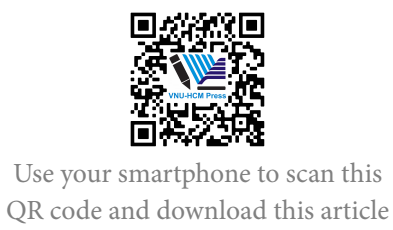

${ }^{\prime}$ Nuclear Technique Laboratory VNUHCM - University of Science, Ho Chi Minh City, Vietnam

${ }^{2}$ Vietnam National University Ho Chi Minh City, Vietnam

${ }^{3}$ Faculty of Physics and Engineering Physics, VNUHCM - University of

Science, Ho Chi Minh City, Vietnam

${ }^{4}$ Faculty of Biology and Biotechnology, VNUHCM - University of Science, Ho Chi Minh City, Vietnam

\section{History}

- Received: 2020-09-11

- Accepted: 2020-12-19

- Published: 2020-12-31

DOI :10.32508/stdj.v23i4.2461

\section{Check for updates}

\section{Copyright}

(c) VNU-HCM Press. This is an openaccess article distributed under the terms of the Creative Commons Attribution 4.0 International license.

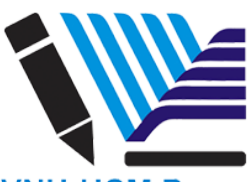

VNU-HCM Press

\begin{abstract}
Introduction: The utilization of fossil fuels in coal-fired power plants (CFPPs) for electricity generation could lead to the release of additional natural radionuclides into the surrounding environment and, consequently, increase the gamma dose rate at these areas. Methods: In this study, the geological variations of gamma dose rate in the vicinity of Duyen Hai CFPP complex and Vinh Tan CFPP complex were evaluated. Results: The obtained gamma dose rates were in the range from 0.07 to $0.22 \mu \mathrm{Sv} \mathrm{h}^{-1}$ with the average value of $0.13 \mu \mathrm{Sv} \mathrm{h}^{-1}$ in Duyen Hai area and in the range from 0.14 to $0.34 \mu \mathrm{Sv} \mathrm{h}{ }^{-1}$ with the average value of $0.21 \mu \mathrm{Sv} \mathrm{h}^{-1}$ in Vinh Tan area. The results indicated that the gamma dose rates in Vinh Tan area are higher than the corresponding values in Duyen Hai area. Both natural aspects, such as the geological differences, geomorphology and weathering process, and anthropogenic aspects, such as the difference in operational scale, coal consumption, and ash discharge between Duyen Hai and Vinh Tan CFPP complexes, might significantly contribute to the variation of gamma dose rate in the investigated areas. Conclusion: Overall, the calculated outdoor annual effective doses in two studied areas showed that the radiological impacts from the operation of Duyen Hai and Vinh Tan CFPP complexes to the environment and public health are now negligible.

Key words: Natural radionuclide, coal-fired power plant, gamma dose rate, spatial distribution, annual effective dose
\end{abstract}

\section{INTRODUCTION}

Radiation and its potential radiological hazards to the surrounding environment and public health are becoming a serious concern around the globe, and radiation itself is an unavoidable part of the environment material (soil, water, plants, ...). The environmental radiation background is mostly caused by the natural radioisotopes $\left({ }^{238} \mathrm{U},{ }^{232} \mathrm{Th}\right.$ series, and $\left.{ }^{40} \mathrm{~K}\right)$, and special attention must be paid to the radioactive inert radon gas $\left({ }^{222} \mathrm{Rn}\right)^{1}$. Human beings may encounter complications of health problems as a result of continuous exposure to natural and artificial radiation. Especially, a certain level of radiation exposure may lead to interaction with human beings at the cellular level and consequently destroy the cell structure.

In recent decades, more attention has been paid to the environmental impacts of coal-burning related to the increase in natural background radiation due to the uranium, thorium content in fly ash and coal slag. Radionuclides are subsequently released into the surrounding area by the pathways in which a fraction of nonvolatile nuclides is enriched and concentrated in the ashes, while the volatile nuclides are well known for their polluting potential due to vast releases of various conventional pollutants like $\mathrm{CO}_{2}, \mathrm{SO}_{x}$, and $\mathrm{NO}_{x}$ into the atmosphere ${ }^{2}$. According to UNSCEAR (1988), the radioactive source released into the atmosphere was related to the proportion of fly ash from the coal-fired power plants ${ }^{3}$. A significant quantity of natural radionuclides can be liberated with fly-ash into the surrounding environment due to the operation of coal-fired power plants ${ }^{2,4}$. Additionally, there are many studies on the effects of radiation from the burning of fossil fuels ${ }^{5-8}$.

In Vietnam, there are currently many CFPPs in operation, with a total power capacity of nearly $14,500 \mathrm{MW}$; each year, they generate about 15.8 million tons of fly ash, slag, and gypsum which are occupying the total landfill area of about 700 ha. Currently, the amount of fly ash and slag consumption of all coal-fired power plants in Vietnam is just over 35\%. The rest are still stored in the dumping sites. No research data on radioactivity levels in the soil surrounding CFPPs and their impact on the environment in Vietnam have been published yet. Therefore, in this study, we initially evaluated the in-situ gamma rate dose distribution in the areas around two typical CFPPs complexes 
in Vietnam: the Vinh Tan CFPP complex in the Central Region and the Duyen Hai CFPP complex at the southern end of Vietnam. From these data, the potential risks of radiation exposure in these two areas were evaluated.

\section{MATERIAL AND METHOD}

\section{Surveyed areas}

Binh Thuan is a province in the middle of Vietnam. Geographical location is from $10^{\circ} 33^{\prime} 42^{\prime \prime}$ to $11^{\circ} 33^{\prime} 18^{\prime \prime}$ North latitude and from $107^{\circ} 23^{\prime} 41^{\prime \prime}$ to $108^{\circ} 52^{\prime} 18^{\prime \prime}$ East longitude. Binh Thuan's geography is mainly low hills, narrow coastal plains, and narrow terrain along northeast-southwest. This area is in a tropical monsoon climate, sunny, windy, no winter, and drought. There are two distinct seasons in this area. The rainy season normally is from May to October, and the dry season lasts from November to April. Vinh Tan CFPP complex, which is located in the Binh Thuan province, was constructed in 2010 and commissioned in 2018. It involved four CFPPs in operation (Vinh Tan 1, Vinh Tan 2, Vinh Tan 4, and Vinh Tan 3). In 2018, the estimated capacity of all plants was up to $4,225 \mathrm{MW}^{9}$. Waste ash and cinder from the operation of these CFPPs are transported to a storage site of an area of about 156.87 hectares.

Tra Vinh is a province in the Mekong Delta. Geographical location is from $9^{\circ} 31^{\prime} 46^{\prime \prime}$ to $10^{\circ} 4^{\prime} 5^{\prime \prime}$ North latitude and $105^{\circ} 57^{\prime} 16^{\prime \prime}$ to $106^{\circ} 36^{\prime} 04^{\prime \prime}$ East longitude. The terrain is mainly flat land with an altitude of $1 \mathrm{~m}$ above sea level. The coastal climate of Tra Vinh province has some meteorological characters such as strong winds, high evaporation, and little rain. Tra Vinh is located in a tropical region with a temperate climate; the average temperature is from 20 to $27^{\circ} \mathrm{C}$; the average humidity is $80-8000 \%$ /year. The rainy season is from May to November, the dry season from December to April of the following year, the average rainfall is from 1,400 - 1,600 mm. Duyen Hai CFPP complex is located in Duyen Hai town, Tra Vinh province. Duyen Hai 1 and Duyen Hai 3 CFPPs include four units; each unit has a capacity of $622.5 \mathrm{MW}$, the total capacity of the units is $2,490 \mathrm{MW}^{9}$.

\section{Inspector 1000}

The Inspector 1000 analyzer is a high-efficiency, handheld $\mathrm{NaI}$ spectrometer which is used primarily in first responder, customs, homeland security, and health physics applications. Inspector 1000 was designed to be used in all types of environmental conditions. It also has a wide operating range for both temperature and humidity. It can be used in any field measurement application requiring radionuclide identification, activity measurements, dose/count rate measurements, or spectrum acquisition and analysis.

\section{Dosimetric quantities}

The in-situ gamma dose rates at the surroundings of the CFPPs in the radius of $3 \mathrm{~km}$ were evaluated at the $1 \mathrm{~m}$ altitude from the ground using the Inspector 1000. Each measurement point was $100 \mathrm{~m}$ apart from the others. As the values of gamma dose rate were performed outdoor and contributed by terrestrial radionuclides and cosmic radiation, the absorbed dose rate and outdoor annual effective dose were calculated in Eq. 1 and 2 by adopting dose conversion factor of Yoshimura (2004), Anjos (2011) and UNSCEAR (2000) for the comparison with other studies.

$$
\begin{gathered}
\mathrm{D}_{\mathrm{ab}}\left(\mu \mathrm{Gy} \mathrm{h}^{-1}\right)=\mathrm{H} *(10) \times 0.8 \times 1 \\
\mathrm{E}_{\text {out }}\left(\mu \mathrm{Sv} \mathrm{y}^{-1}\right)=\mathrm{D}_{\mathrm{ab}} \times 0.7 \times 8760 \times 0.2
\end{gathered}
$$

where: $\mathrm{D}_{a b}\left(\mu \mathrm{Gy} \mathrm{h}^{-1}\right)$ is absorbed dose rate; $\mathrm{H}^{\star}(10)$ $\left(\mu \mathrm{Sv} \mathrm{h}{ }^{-1}\right)$ is in-situ gamma dose rate; $0.8\left(\mathrm{~Gy} \mathrm{~Sv}^{-1}\right)$ is conversion coefficient from gamma dose rate to air kerma; 1 is conversion coefficient from air kerma to absorbed dose rate; $\mathrm{E}_{\text {out }}\left(\mu \mathrm{Sv} \mathrm{y}^{-1}\right)$ is outdoor annual effective dose due to terrestrial radionuclides and cosmic radiation; $0.7\left(\mathrm{~Sv} \mathrm{~Gy}^{-1}\right)$ is the conversion factor from absorbed dose rate to effective dose; $8760(\mathrm{~h})$ is the total amount of a year; 0.2 is outdoor occupancy factor $^{10-12}$.

\section{Statistical analysis and mapping}

Descriptive analysis, normality test, and one-way ANOVA test were performed for statistical estimation and comparison between two sets of data; a p-value of less than 0.05 is considered as statistically significant. In-situ measured gamma dose rates were interpolated using the kriging method in Surfer software, which is suitable for gamma spectrometric data ${ }^{13}$.

\section{RESULTS}

\section{Geological variation of gamma dose rates}

The in-situ gamma dose rate measurements around two surveyed CFPP complexes were performed using the Inspector 1000 spectrometer. There were 114 measurements for Duyen Hai CFPP complex and 116 measurements for Vinh Tan CFPP complex. These gamma dose rate values were statistically analyzed and given in Table 1. The occurrence frequency distributions of these values were given in Figure 1. The normality of the gamma dose rate data was tested by 
using the Anderson-Darling test. The results were found that the distribution of gamma dose rate in both Duyen Hai and Vinh Tan area are non-normal $(p<0.05)$. The results indicated the non-uniform distribution of gamma dose rates in investigated areas, possibly due to the geological properties. The overall gamma dose rate values in the two areas are generally low as the distributions are left-skewed. Figure 2 showed the spatial distribution of gamma dose rate in the vicinity of Duyen Hai CFPP and Vinh Tan CFPP. As shown in Figure 2, some high dose locations close to maximum dose values were indicated with darker red colour; more specifically, Duyen Hai area showed some high dose locations in the North and the West and Vinh Tan area showed some high dose locations in the Northwest. The values were in the range from 0.07 to $0.22 \mu \mathrm{Sv} \mathrm{h}{ }^{-1}$ with the average value of 0.13 $\pm 0.03 \mu \mathrm{Sv} \mathrm{h}^{-1}$ for Duyen Hai area and in the range from 0.14 to $0.34 \mu \mathrm{Sv} \mathrm{h}{ }^{-1}$ with the average value of $0.21 \pm 0.04 \mu \mathrm{Sv} \mathrm{h}^{-1}$ for Vinh Tan area. The result of the one-way ANOVA test showed a significant difference between the gamma dose rates in Duyen Hai area and those in Vinh Tan area $(\mathrm{p}<0.05)$.

\section{Absorbed dose rate and outdoor annual ef- fective dose}

The calculation of the absorbed dose rate and the outdoor annual effective dose in this study as well as the comparison with other studies over the world, have been made and presented in Table 2. The calculated absorbed dose rates were found in the range from 0.06 to $0.16 \mu \mathrm{Gy} \mathrm{h}^{-1}$ with the average value of $0.11 \mu \mathrm{Gy}$ $\mathrm{h}^{-1}$ for Duyen Hai area and in the range from 0.11 to $0.27 \mu \mathrm{Gy} \mathrm{h}^{-1}$ with the average value of $0.17 \mu \mathrm{Gy}$ $\mathrm{h}^{-1}$ for Vinh Tan area. In the meanwhile, the outdoor annual effective doses were in the range from 0.07 to $0.22 \mathrm{mSv} \mathrm{y}^{-1}$ with the average value of $0.13 \mathrm{mSv} \mathrm{y}^{-1}$ for Duyen Hai area and in the range from 0.14 to 0.33 $\mathrm{mSv} \mathrm{y}^{-1}$ with the average value of $0.21 \mathrm{mSv}^{-1}$ for Vinh Tan area.

\section{DISCUSSION}

The radiation sources are mainly from the natural radioactivity synthesized during the creation of the solar system, in which radionuclides in thorium series, uranium-series and ${ }^{40} \mathrm{~K}$ contribute mostly to the ambient dose rate of the studied areas ${ }^{13}$. Other sources that can be taken into account for the contribution to the gamma dose rate are the radiations from the cosmic ray and cosmogenic radionuclides ${ }^{12,18}$. Obtained from Figure 2, the spatial distributions of gamma dose rates are non-uniformly for each studied area: Low and middle dose rates were found at most locations. However, there are some high gamma dose rate locations in the North and West of the CFPP for Duyen Hai area and in the Northwest of the CFPP for Vinh Tan area.

The distribution of natural radionuclides is affected by many factors, both natural and anthropogenic facets. Firstly, the natural aspects, such as geological formation as well as weathering and geomorphology, could significantly vary the radioactivity concentration of natural radionuclides ${ }^{13,16-20}$. Secondly, the anthropogenic impacts, in this case, are the content of enhanced radionuclides in ash in the nearby dumping area; and the fallout and transportation of fly ash and its progenies by different wind directions ${ }^{4}$. During the combustion, the radioactive contents in ash increase to a certain extent in comparison with those in feed coals, which is expressed by enrichment factor - the ratio between activity concentration in ash and activity concentration in feed coal ${ }^{21-23}$. The degree of enrichment depends on many factors such as particle size and CFPP technology, particularly, the enrichment factor in fly ash is considered to be higher than those in bottom ash as many researchers previously investigated ${ }^{21,24}$.

As observed from Table 1, the average gamma dose rate of Duyen Hai area is slightly lower than the corresponding value of Vinh Tan area. Significant differences among the gamma dose rate values of Duyen Hai and Vinh Tan were found according to the oneway ANOVA test $(p<0.05)$. There are many aspects related to the difference in dose rate between the two studied areas. One possible explanation could be the difference in geological characteristics between the two studied areas ${ }^{16}$. The rock lithology, such as composition, grain size, and origin, could influence radioelement content in soil and, consequently, lead to the variation of gamma dose rate in different locations ${ }^{13}$. Differences between radioactivity concentrations in two areas were reported by Huy et al. $(2012)^{25}$, in which the radioactivity concentration of three main radiation sources $-{ }^{226} \mathrm{Ra},{ }^{232} \mathrm{Th}$, and ${ }^{40} \mathrm{~K}$ are $41.56,37.96$, and $415.21 \mathrm{~Bq} \mathrm{~kg}^{-1}$ for Binh Thuan province and are 26.5, 61.0 and $414.6 \mathrm{~Bq} \mathrm{~kg}^{-1}$ for Tra Vinh province, respectively. The difference due to the cosmic rays in the two locations was negligible as these two locations are coastal areas with low elevation $^{12}$. Moreover, the discrepancy in each CFPP capacity could affect the variation of gamma dose rate in this study. In 2019, the total capacity of Vinh Tan CFPP complex is up to $4225 \mathrm{MW}$, higher than the corresponding value of $2490 \mathrm{MW}$ of Duyen Hai CFPP complex with similar pulverised combustion 
Histogram (with Normal Curve) of gamma dose rate in Duyen Hai

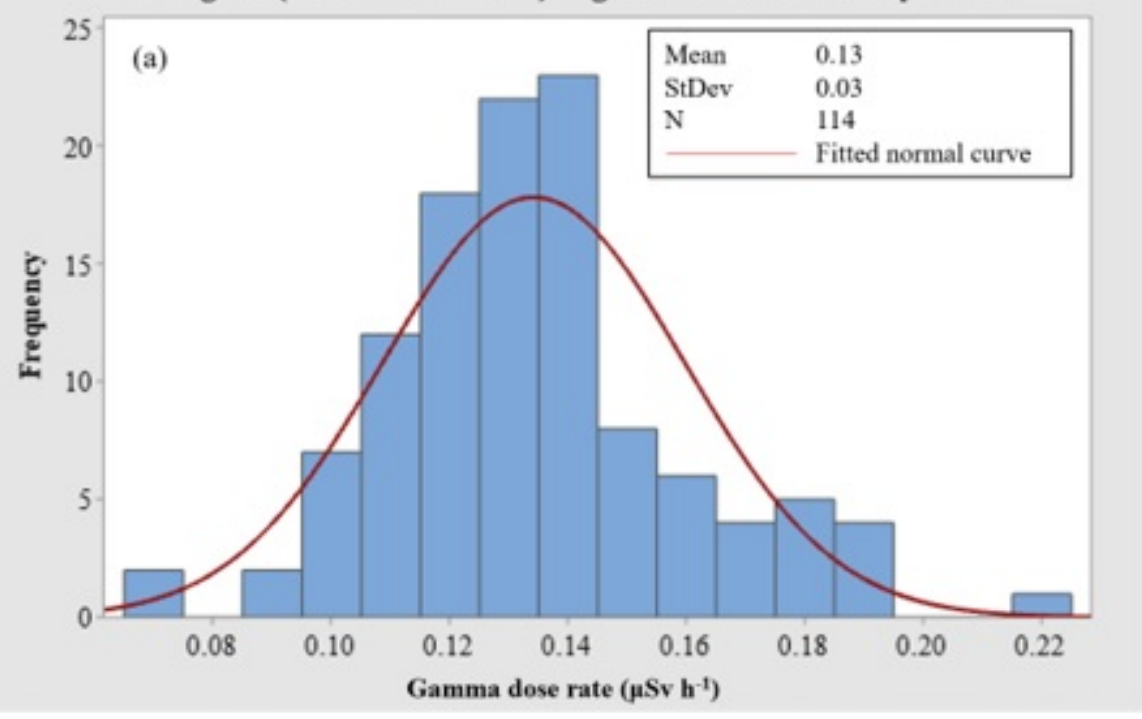

Histogram (with Normal Curve) of gamma dose rate in Vinh Tan

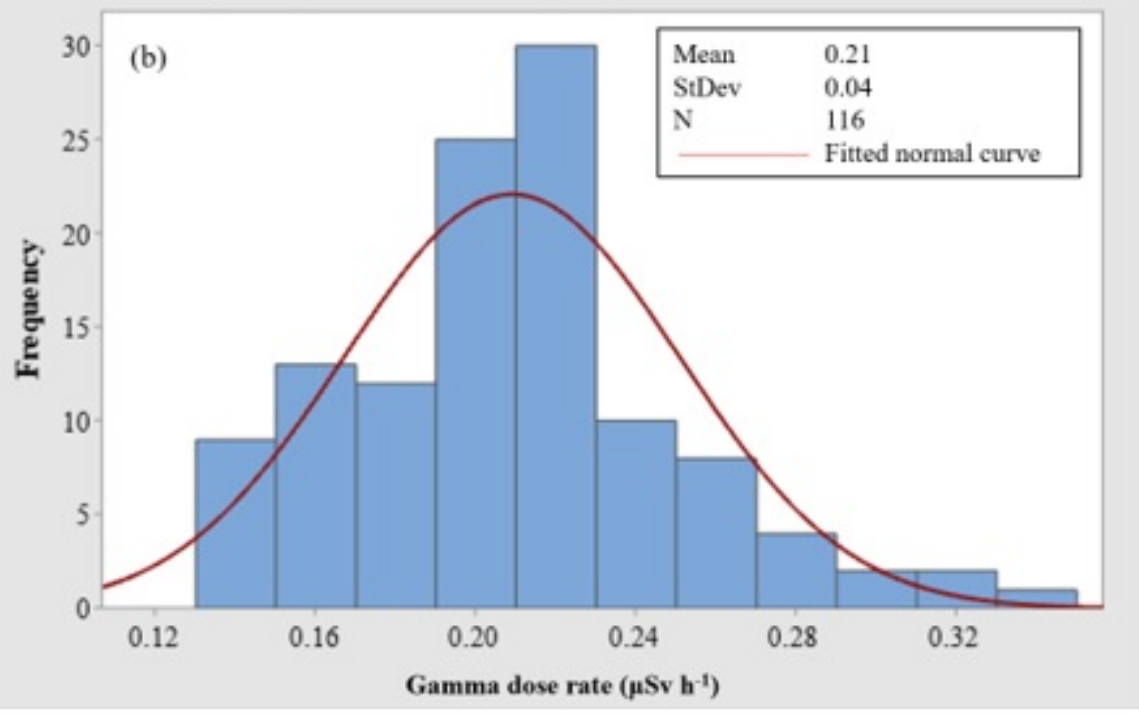

Figure 1: (a) Histogram of the gamma dose rate distribution in Duyen Hai area (b) Histogram of the gamma dose rate distribution in Vinh Tan area. The $y$-axis is the occurrence frequency and the $x$-axis is the measured gamma dose rate; The red curve is the expected normal distribution obtained from fitting the experimental data according to Gaussian distribution; Mean is the mean value of the distribution; StDev is the standard deviation value of the distribution; $N$ is sample size. 

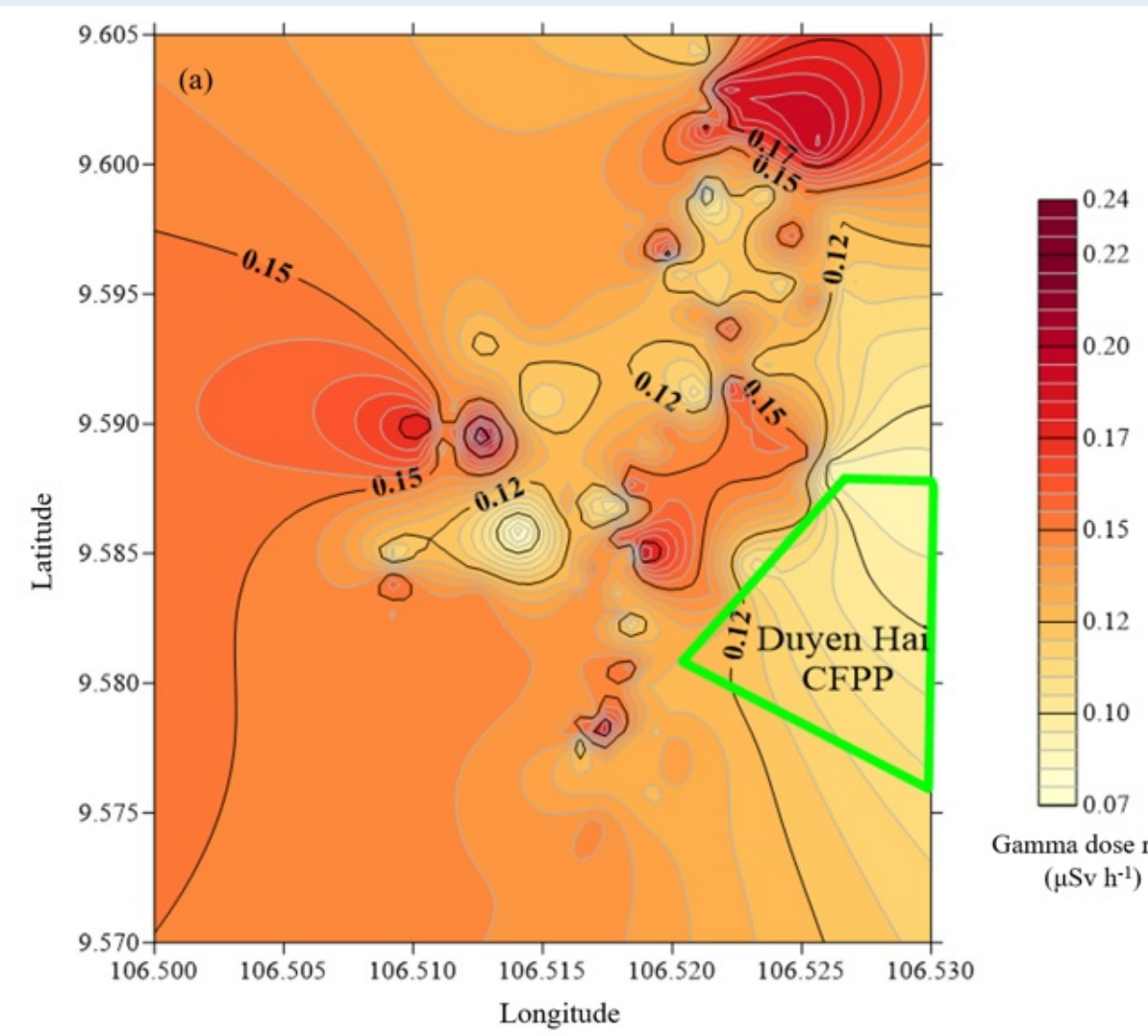

Gamma dose rate $\left(\mu \mathrm{Sv} \mathrm{h} \mathrm{h}^{-1}\right)$
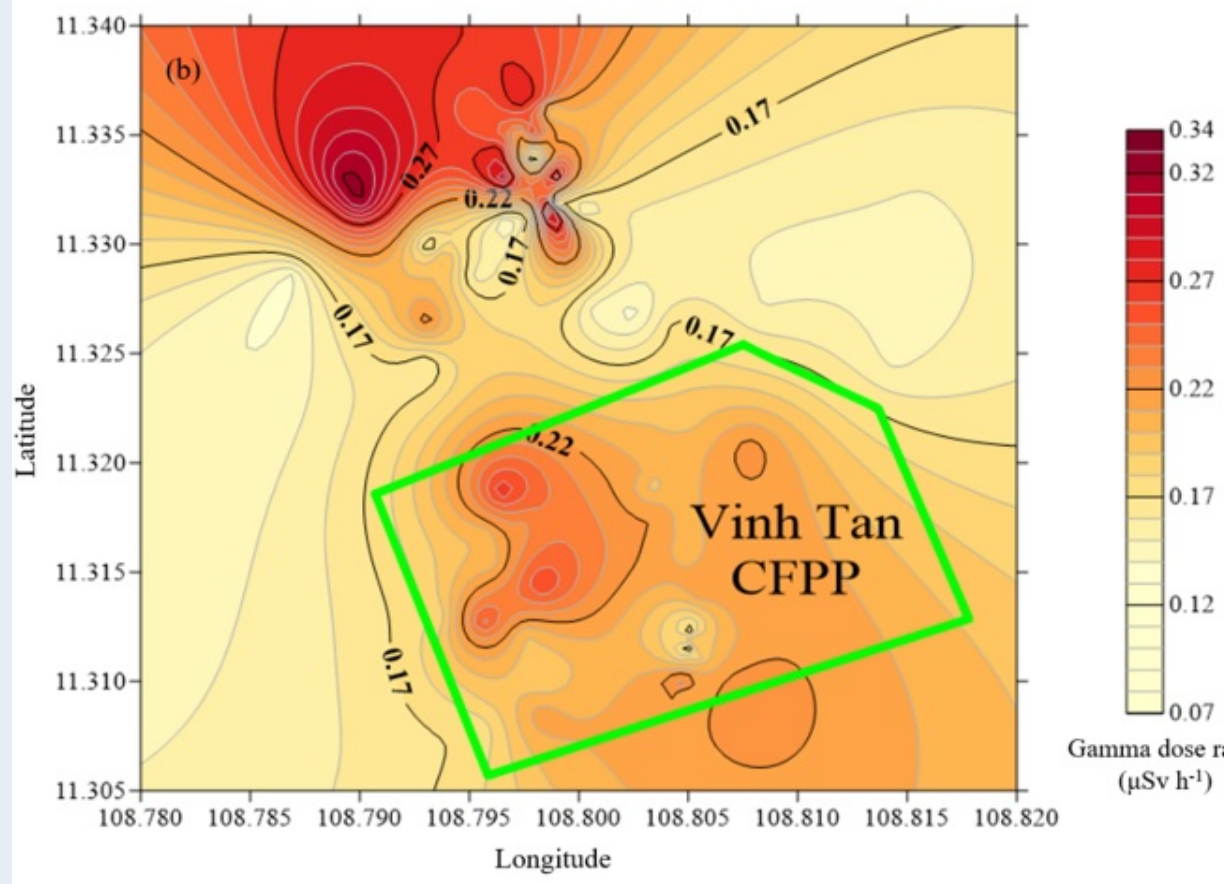

Gamma dose rate $\left(\mu \mathrm{Sv} \mathrm{h} \mathrm{h}^{-1}\right)$

Figure 2: (a) Spatial distribution of gamma dose rate $\left(\mu \mathrm{Sv} \mathrm{h}^{-1}\right)$ in Duyen Hai area and (b) Spatial distribution of gamma dose rate $\left(\mu \mathrm{Sv} \mathrm{h}^{-1}\right)$ in Vinh Tan area. The $y$-axis is the latitude and the $\mathrm{x}$-axis is the longitude for two studied areas. The color scale indicates the low or high level of gamma dose rate. The figures in the map indicate the values of the measured gamma dose rate which were interpolated into the isodose line by kriging method in Surfer software. 


\begin{tabular}{|c|c|c|c|c|c|c|c|c|}
\hline & $\begin{array}{l}\text { Sample } \\
\text { size } \\
(\mathrm{N})\end{array}$ & $\begin{array}{l}\text { Average } \\
\text { gamma dose } \\
\text { rate }(\mu \mathrm{Sv} \\
\text { h-1 })\end{array}$ & $\begin{array}{l}\text { Standard } \\
\text { devia- } \\
\text { tion }\end{array}$ & CV (\%) & Min & $\operatorname{Max}$ & $\begin{array}{l}\text { Anderson- } \\
\text { Darling } \\
\text { test }\end{array}$ & $\begin{array}{l}\text { One-way } \\
\text { ANOVA } \\
\text { test }\end{array}$ \\
\hline $\begin{array}{l}\text { Duyen } \\
\text { Hai }\end{array}$ & 114 & 0.13 & 0.03 & 19.01 & 0.07 & 0.22 & $\mathrm{p}<0.05$ & $\mathrm{p}<0.05$ \\
\hline Vinh Tan & 116 & 0.21 & 0.04 & 20.06 & 0.14 & 0.34 & $\mathrm{p}<0.05$ & \\
\hline
\end{tabular}

Table 2: Comparison of gamma dose rates in different studies

\begin{tabular}{|c|c|c|c|}
\hline & $\begin{array}{l}\text { Gamma dose rate } \\
\text { (Terrestrial and cosmic) } \\
(\mu \mathrm{Sv} \text { h-1) }\end{array}$ & $\begin{array}{l}\text { Absorbed dose rate } \\
\text { (Terrestrial and cosmic) } \\
(\mu \mathrm{Gy} \mathrm{h-1)}\end{array}$ & $\begin{array}{l}\text { Outdoor annual effective } \\
\text { dose } \\
\text { (Terrestrial and cosmic) } \\
(\mathrm{mSv} \text {-1) }\end{array}$ \\
\hline $\begin{array}{l}\text { Duyen Hai } \\
\text { (present study) }\end{array}$ & $0.13(0.07-0.22)$ & $0.11(0.06-0.16)$ & $0.13(0.07-0.22)$ \\
\hline $\begin{array}{l}\text { Vinh Tan } \\
\text { (present study) }\end{array}$ & $0.21(0.14-0.34)$ & $0.17(0.11-0.27)$ & $0.21(0.14-0.33)$ \\
\hline Brazil $^{10}$ & $0.06-0.18$ & & \\
\hline Korea $^{14}$ & 0.18 & 0.08 & \\
\hline India ${ }^{15}$ & & $0.10-0.15$ & $0.13-0.25$ \\
\hline Hungary ${ }^{16}$ & $0.10(0.05-0.21)$ & & \\
\hline Malaysia $^{17}$ & & $0.17(0.03-0.7)$ & 0.21 \\
\hline Reference value $^{12}$ & & & 0.46 \\
\hline
\end{tabular}

technology ${ }^{9}$. Therefore, the coal demand and consequently, the amount of fly ash and slag discharged into the environment from Vinh Tan CFPPs might be higher than those from Duyen Hai CFPPs. The previous study of Inoue et al. $(2020)^{26}$ also showed that the absorbed dose rate $\left(65 \mathrm{nGy} \mathrm{h}^{-1}\right)$ in Binh Thuan province was higher than the corresponding value (54 $n G y h^{-1}$ ) in Tra Vinh province.

The results of the calculation of absorbed dose rate and outdoor annual effective dose in Table 2 showed good agreement with other studies. According to UNSCEAR (2000), cosmic radiation and outdoor terrestrial radionuclides contribute to the total annual effective dose, an amount of 0.39 and $0.07 \mathrm{mSv}^{-1}$, respectively $^{12}$. Therefore, the reference value of $0.46 \mathrm{mSv}$ $\mathrm{y}^{-1}$ for outdoor annual effective dose due to cosmic radiation and terrestrial radionuclides was adopted. The outdoor annual effective doses in Duyen Hai and Vinh Tan area are lower than the reference value by UNSCEAR (2000) of $0.46 \mathrm{mSv} \mathrm{y}^{-1}$ and other studies in India (from 0.13 to $0.25 \mathrm{mSv} \mathrm{y}^{-1}$ ) and Malaysia $\left(0.21 \mathrm{mSv} \mathrm{y}^{-1}\right)$. Therefore, the conclusion could be made that the operation of CFPPs in these two areas might do no radiological harm to the public and environment.

In general, the radiological investigations have only been performed representatively for each province, not for each specific CFPP area with a high number of samples. Based on the results of this preliminary study, we could further investigate radioactive content in the soil samples that correspond with the locations that contain high gamma dose rates. Therefore, precise conclusions of soil contamination sources could be reached. And recommendations for dosimetric safety could be made for specific residents and workers in different scenarios in the studied area. Moreover, despite the low gamma dose rate in the two studied areas, CFPPs still affect the environment and public to a certain extent. By performing dose rate measurement on a larger scale and estimating weather parameters such as wind direction, humidity, etc..., the distribution of fly ash discharged from the CFPP could be evaluated. These data are important inputs for precise simulations of the effect of CFPP on the surrounding area in both normal operation cases and accident cases. However, due to the difficulties of 
sampling in some craggy terrain and restricted areas in CFPP zone, sampling points were not distributed uniformly in the studied area. Therefore, some interpolated results might be slightly different from practical results.

\section{CONCLUSION}

This study provided preliminary results of the in-situ gamma dose rate in the vicinity of two CFPP complexes in Vietnam with the average values of $0.13 \mu \mathrm{Sv}$ $\mathrm{h}^{-1}$ for Duyen Hai area and $0.21 \mu \mathrm{Sv} \mathrm{h}{ }^{-1}$ for Vinh Tan area. The variation of spatial distributions in each CFPP area is contributed by both natural and anthropogenic factors. Natural factors are the geological formation, weathering, and geomorphology processes. Meanwhile, the impacts of CFPP on the surrounding area, such as the containment of ash in the landfill area and the release of fly ash into the atmosphere, could be taken into account as anthropogenic factors to the environment. The results indicated that the average gamma dose rate in Vinh Tan CFPP complex is higher than the corresponding value in Duyen Hai CFPP complex. Many aspects that contributed to this difference are the geological characteristics that lead to the high natural background radiation of Binh Thuan province and the bigger scale of Vinh Tan CFPP complex in comparison with the scale of Duyen Hai CFPP complex. The overall annual effective doses in the two studied areas are $0.13 \mathrm{mSv} \mathrm{y}^{-1}$ and $0.21 \mathrm{mSv} \mathrm{y}^{-1}$ for Duyen Hai and Vinh Tan area, respectively, which are lower than the recommended value of $0.46 \mathrm{mSv} \mathrm{y}^{-1}$ by UNSCEAR. Therefore, the radiological risks in the two studied areas negligible to the environment and public. However, as this is a preliminary study of insitu gamma dose rate, closer investigations of specific radionuclides content in the vicinity of two studied CFPPs are needed for precise assessments of the radiological impact of CFPPs to the public and environment.

\section{AUTHOR'S CONTRIBUTION}

Truong Thi Hong Loan, Vu Ngoc Ba designed the ideas for the study, planned for the experiments.

$\mathrm{Vu}$ Ngoc Ba, Bui Ngoc Thien, Truong Thi Xuan Truong, Nguyen Quang Dao performed the in-situ measurements.

Vu Ngoc Ba, Bui Ngoc Thien, Truong Thi Hong Loan derived the models, and analyzed the data, wrote the manuscript.

All authors provided critical feedback, discussion, and helped shape the research, analysis for the manuscript.

\section{ABBREVIATIONS}

ANOVA: analysis of variance

CFPP: coal-fired power plant

UNSCEAR: United Nations Scientific Committee on the Effects of Atomic Radiation

\section{COMPETING INTERESTS}

The authors declare that they have no competing interests.

\section{ACKNOWLEDGEMENT}

This research is granted by National Foundation for Science and Technology Development (Nafosted) under the Number 103.04-2018.61. The authors would like to express our sincere thanks to Prof. Dr. Sc. Nguyen Ngoc Tran, the Director Board of EVN Group, the Director Boards of Vinh Tan 2 and Duyen Hai 3 CFPPs for your helps in our sampling and doing in-situ measurements. The authors would like to thank the reviewers, and editors for their thorough review and highly appreciated comments and suggestions, which significantly contributed to improving the quality of this manuscript.

\section{REFERENCES}

1. UNSCEAR. Sources and Effects of lonizing Radiation. Report to General Assembly, Annex B. United Nations, New York. 2008;

2. Uslu I, Gökmeşe F. Coal An Impure Fuel Source: Radiation Effects of Coal-fired Power Plants in Turkey. Hacettepe J. Biol. \& Chem. 2010;38(4):259-268.

3. UNSCEAR. Sources, Effects and Risks of lonizing radiation. New York: United Nations. 1988;p. 81-84.

4. Flues M, Moraes V, Mazzilli BP. The influence of a coalfired power plant operation on radionuclide concentrations in soil. Journal of Environmental Radioactivity. 2002;63:285294. Available from: https://doi.org/10.1016/S0265-931X(02) 00035-8.

5. Man-yin TW, Leung JKC. Radiological impact of coal ash the power plants in Hong Kong. Journal of Environmental Radioactivity. 1996;30(1):1-14. Available from: https://doi.org/ 10.1016/0265-931X(95)00042-9.

6. Papastefanou C. Radiation impact from lignite burning due to 226Ra in Greek coal-fired power plants. Health Physics. 1996;70(2):187-191. PMID: 8567285. Available from: https: //doi.org/10.1097/00004032-199602000-00005.

7. Ayc, ik GA, Ercan A. Radioactivity measurements of coals and ashes from coal-fired power plants in the Southwestern part of Turkey. Journal of Environmental Radioactivity. 1997;35(1):23-35. Available from: https://doi.org/10.1016/ S0265-931X(96)00031-8.

8. Bem EM, Bem H. Studies of radionuclide concentration in surface soil in and around fly ash disposal sites. The Science of the Total Environment. 1998;220:215-222. Available from: https://doi.org/10.1016/S0048-9697(98)00258-7.

9. ;Available from: https://endcoal.org/global-coal-plant-tracker/ 2020.

10. Yoshimura EM, Otsubo SM, \& Oliveira RER. Gamma ray contribution to the ambient dose rate in the city of São Paulo, Brazil. Radiation Measurements. 2004;38(1):51-57. Available from: https://doi.org/10.1016/S1350-4487(03)00283-X. 
11. Anjos RM, Juri Ayub J, Cid AS, Cardoso R \& Lacerda T. External gamma-ray dose rate and radon concentration in indoor environments covered with Brazilian granites. Journal of Environmental Radioactivity. 2011;102(11):1055-1061. PMID: 21729819. Available from: https://doi.org/10.1016/j.jenvrad. 2011.06.001.

12. UNSCEAR. Sources and Effects of lonizing Radiation, New York: United Nations. 2000;.

13. IAEA. IAEA-TECDOC-1363 Guidelines for radioelement mapping using gamma ray spectrometry data. 2003;

14. Cho JH, Lee HK, Dong KR, Ju YJ, Chung WK, Han DK \& Kim $\mathrm{MH}$. A study on the measurement and analysis of radioactivity concentration and the ambient dose rate in soil on the playgrounds of elementary schools in the Gwangju area. Environmental Earth Sciences. 2013;71(5):2391-2397. Available from: https://doi.org/10.1007/s12665-013-2639-x.

15. Karunakara N, Yashodhara I, Sudeep Kumara K, Tripathi RM, Menon SN, Kadam S \& Chougaonkar MP. Assessment of ambient gamma dose rate around a prospective uranium mining area of South India - A comparative study of dose by direct methods and soil radioactivity measurements. Results in Physics. 2014;4:20-27. Available from: https://doi.org/10.1016/ j.rinp.2014.02.001.

16. Torres SB, Petrik A, Szabó KZ, Jordan G, Yao J \& Szabó C. Spatial relationship between the field-measured ambient gamma dose equivalent rate and geological conditions in a granitic area, Velence Hills, Hungary: An application of digital spatial analysis methods. Journal of Environmental Radioactivity. 2018;192:267-278. PMID: 29990774. Available from: https: //doi.org/10.1016/j.jenvrad.2018.07.001.

17. Saleh MA, Ramli AT, Hamzah KB, Zainal J, Sies MM, Gabdo HT \& Garba NN. In situ measurement of terrestrial gamma dose rates in eastern region of Peninsular Malaysia and its relation to geological formation and soil types. Radiochimica Acta. 2019;107(6). Available from: https://doi.org/10.1515/ ract-2018-2950.

18. Bossew $P$, Cinelli G, Hernández-Ceballos $M$, Cernohlawek $N$, Gruber V, Dehandschutter B, Menneson F, Bleher M, Stohlker U, Hellmann I, Weiler F, Tollefsen T, Tognoli PV, de Cort M. Estimating the terrestrial gamma dose rate by decomposition of the ambient dose equivalent rate. Journal of Environmental Radioactivity. 2017;166:296-308. PMID: 26926960. Available from: https://doi.org/10.1016/j.jenvrad.2016.02.013.

19. Dragović $S$, Janković-Mandić L, Dragović $R$, Đorđević M, Đokić $M \&$ Kovačević J. Lithogenic radionuclides in surface soils of
Serbia: Spatial distribution and relation to geological formations. Journal of Geochemical Exploration. 2014;142:4-10. Available from: https://doi.org/10.1016/j.gexplo.2013.07.015.

20. Cujić M, Dragović S, Đorđević M, Dragović R, Gajić B \& Miljanić Š. Radionuclides in the soil around the largest coalfired power plant in Serbia: radiological hazard, relationship with soil characteristics and spatial distribution. Environmental Science and Pollution Research. 2015;22(13):10317-10330. PMID: 25716901. Available from: https://doi.org/10.1007/ s11356-014-3888-2.

21. Sahu SK, Tiwari M, Bhangare RC \& Pandit GG. Enrichment and particle size dependence of polonium and other naturally occurring radionuclides in coal ash. Journal of Environmental Radioactivity. 2014;138:421-426. PMID: 24813148. Available from: https://doi.org/10.1016/j.jenvrad.2014.04.010.

22. Ozden B, Guler E, Vaasma T, Horvath $M$, Kiisk $M$ \& Kovacs $T$. Enrichment of naturally occurring radionuclides and trace elements in Yatagan and Yenikoy coal-fired therma power plants, Turkey. Journal of Environmental Radioactivity. 2018;188:100-107. PMID: 28965987. Available from: https: //doi.org/10.1016/j.jenvrad.2017.09.016.

23. Temuujin J, Surenjav E, Ruescher C \& Vahlbruch JAN. Processing and uses of fly ash addressing radioactivity (Critical Review). Chemoshpere. 2018;216:866-882. PMID: 30390998. Available from: https://doi.org/10.1016/j.chemosphere.2018. 10.112.

24. Gür F \& Yaprak G. Natural radionuclide emission from coalfired power plants in the southwestern of Turkey and the population exposure to external radiation in their vicin ity. Journal of Environmental Science and Health, Part A 2010;45(14):1900-1908. PMID: 20981605. Available from: https://doi.org/10.1080/10934529.2010.520608.

25. Huy NQ, Hien PD, Luyen TV, Hoang DV, Hiep HT, Quang NH, Long NQ, Nhan DD, Binh NT, Hai PS, Ngo NT. Natural radioactivity and external dose assessment of surface soils in Vietnam. Radiation Protection Dosimetry. 2012;151(3):522-531. PMID: 22434923. Available from: https://doi.org/10.1093/rpd/ncs033.

26. Inoue K, Fukushi M, Van Le T, Tsuruoka H, Kasahara S \& Nimelan V. Distribution of gamma radiation dose rate related with natural radionuclides in all of Vietnam and radiological risk assessment of the built-up environment. Scientific Reports. 2020;10(1). PMID: 32709939. Available from: https://doi.org/ 10.1038/s41598-020-69003-0. 